\title{
GRAMSCI E O DEBATE DA DERIVAÇÃO DO ESTADO: O CONCEITO DE HEGEMONIA EM JOACHIM HIRSCH E BOB JESSOP
}

\author{
GUSTAVO CARNEIRO DA SILVA ${ }^{1}$
}

\begin{abstract}
Resumo: Este artigo visa apresentar o modo como a obra de Antonio Gramsci foi incorporada por autores marxistas que compóem o debate a respeito da derivação do Estado a partir das categorias da crítica do valor propos tas por Karl Marx. Para tanto, o foco será dado ao conceito de "hegemonia" conforme proposto por Gramsci, por entendê-lo como central dentro de sua teoria política. Será abordada a forma como tal conceito foi mobiliza do por Joachim Hirsch e Bob Jessop, dois autores que participaram do referido debate e que produziram importantes e antagônicas contribuiçôes para as análises marxistas a respeito da natureza do Estado capitalista.
\end{abstract}

Palavras-chave: Gramsci; Hirsch; Jessop; Hegemonia; Derivação.

1 INTRODUÇÃO

Na década de 1970, um grupo de pensadores da Alemanha Ocidental e da GrãBretanha começou a desenvolver um novo marco a respeito do tratamento dado ao Estado pela teoria marxista. Buscando superar as concepçôes teóricas dominantes à época, oriundas tanto do keynesianismo como do marxismo oficial elaborado na União Soviética, tais autores propuseram uma volta às categorias marxianas para a construção de uma teoria materialista a respeito do fenômeno estatal.

Tal discussão ficou conhecida como debate da derivação do Estado, por conta da tentativa de derivação de uma teoria materialista do Estado a partir de uma apreensão das categorias marxianas de crítica à economia política. Tentava-se, com isso, erigir uma teoria que respondesse ao contexto político europeu da década de 1970. Naquele momento, a Europa Ocidental era marcada pelo declínio do Estado de bem-estar social do pós-guerra, com a aber-

1 Graduando em Direito pela Universidade de São Paulo. Bacharel em História pela Universidade de São Paulo.

gustavo.carneiro.silva@usp.br 
tura de períodos recessivos em diversos países e novas ofensivas contra as forças de esquerda, potencializadas pelo progressivo enfraquecimento da URSS e a retomada da hegemonia estadunidense. Na Alemanha, o Partido Social-Democrata ganhou as eleiçóes de 1969, reforçando o credo reformista justamente na conjuntura mais desfavorável à implementação de tais ideias desde o fim da Segunda Guerra (OSÓRIO, 2019, p. 20-21). Assim, um grupo de autores se dedicou ao aprofundamento dos estudos a respeito do caráter do Estado capitalista, analisando sua configuração como um elemento intrínseco às relações de produção capitalistas.

Um dos grandes trunfos do debate foi o desenvolvimento da compreensão a respeito do Estado enquanto forma política, isto é, como uma relação social que se manifesta a partir de uma forma específica que a coloca de maneira exterior e oposta aos indivíduos e oculta sua essência. Em O capital (2011), Marx se dedicou a estudar a forma valor, forma social que oculta a extração do mais valor e a exploração existentes na base dos processos capitalis tas de produção. Assim, os autores do debate da derivação buscaram construir uma compreensão do Estado enquanto forma politica do capitalismo, derivada da forma valor e das relaçôes de produção capitalistas e calcada, em síntese grosseira, na necessidade existente nesse modo de produção de afastamento da coerção física do seio das relações de produção para que a livre troca de mercadorias, entre elas a força de trabalho, possa ocorrer.

Com isso, tem-se a separação formal da dominação econômica e da dominação política, surgindo uma forma política, o Estado, que se coloca formalmente apartada da sociedade e das classes sociais que a compõem. Dois importantes autores que se inscreveram no debate sintetizam da seguinte forma a importância de tais avanços teóricos:

Não é que a "análise da forma” represente uma "estrada da realeza para a ciência"
em que não se encontrará obstáculos para a compreensão da política: se o leitor en-
contra o debate, por vezes, demasiado formal e abstrato, essas críticas são, em parte,
justificadas. O maior avanço da abordagem da "análise da forma" não decorre da
resolução de todos os problemas da teoria marxista do Estado, mas de ter estabele-
cido o pré-requisito essencial para a compreensão do Estado com base na dialética
da forma e do conteúdo da luta de classes. A análise da forma isolada não é sufici-
ente, mas enquanto o problema da forma é ignorado, uma abordagem adequada
para o Estado não é apenas possível. (HOLLOWAY \& PICCIOTTO, 1978, p. 30)

Como colocam os próprios autores, a análise da forma política representa um marco teórico essencial para a compreensão do Estado capitalista, mas não é capaz de explicar integralmente o fenômeno político. Não sendo possível derivar todo o conteúdo e as funções do Estado apenas a partir de categorias oriundas da crítica marxista da economia política, é 
preciso, portanto, explicá-los a partir de outros fatores. Assim, faz-se necessário entender a dinâmica da luta de classes e seus efeitos sobre o nível político.

Entre as inúmeras divergências sustentadas pelos autores que participaram do debate, o lugar da luta de classes na análise materialista do Estado foi um dos principais. Isso porque toca em uma questão fundamental ao debate: descobrir quais são "os mecanismos existentes por meio dos quais a burguesia consegue manter-se como classe dominante e reproduzir as condições de reprodução do capitalismo" (CALDAS, 2015, p. 202).

Nessas discussões, um autor muito revisitado pelos participantes do debate foi Antonio Gramsci. Seu pioneirismo nas reflexóes a respeito da autonomia relativa da política e do Estado, buscando superar a leitura influente realizada por autores como Gueorgui Plekhanov da metáfora marxiana da base/superestrutura, fez de sua obra um marco da análise marxista a respeito da política. Assim, as categorias gramscianas foram mobilizadas por diversos autores do debate da derivação para a compreensão da relação entre a luta de classes e o Estado.

O presente trabalho terá como objetivo abordar alguns aspectos da apropriação do arsenal teórico de Gramsci pelos autores derivacionistas. Dada a necessidade de precisão do objeto de análise, teremos como foco o conceito de hegemonia de Gramsci, categoria central em sua obra, apropriada de distintas maneiras por diversos autores que trataram do tema da luta de classes no debate em questão.

Por vezes, o estudo do Estado capitalista a partir da derivação das categorias da crítica da economia política marxista é apontado como economicista ou formalista (MÍGUEZ, 2010, p. 654), motivo pelo qual acreditamos ser pertinente a análise aqui proposta. Abordaremos a apropriação do conceito de hegemonia por dois participantes do debate: $o$ alemão Joachim Hirsch e o britânico Bob Jessop. A escolha de ambos se dá por serem autores relevantes que desenvolveram visões distintas a respeito da relação entre o Estado enquanto forma política e o Estado enquanto instituição que se materializa no terreno da luta de classes.

\section{GRAMSCI E O CONCEITO DE HEGEMONIA}

Os escritos de Antonio Gramsci foram alvo de diversas apropriaçôes, muitas contraditórias entre si. O caráter fragmentário da sua obra, devido à escrita precária no cárcere, facilita leituras seletivas e descontextualizadas. A primeira edição italiana dos seus escritos carcerários ilustra bem isso, com a quebra da historicidade dos manuscritos em prol de uma organi- 
zação temática, somada com uma tentativa de transformá-los em algo palatável ao marxismo soviético oficial do final da década de 1940 (DIAS, 1996b, p. 108-110).

O conceito de hegemonia, central em sua obra, foi um dos principais alvos de usos descontextualizados. Retirando-o da organicidade do seu pensamento, voltado sempre para a realidade política de sua época e para o objetivo estratégico de triunfo do comunismo na Itália e em toda a Europa, é comum ver o conceito de hegemonia identificado como um simples domínio ideológico, como aponta Dias (1996a, p. 114).

Assim, partiremos de uma breve contextualização do conceito de hegemonia na obra gramsciana. De início, Gramsci (1999, t.2, p. 177) tributa a Lenin a criação do conceito de hegemonia, destacando que fora essa sua principal contribuição ao marxismo. Gramsci, então, busca desenvolver o conceito, trabalhando-o em relação a uma multiplicidade de temas, tais como economia, religião e cultura, conforme apontado por Dias (1996a, p. 10).

Ao longo das diferentes aparições da hegemonia nos Cadernos do Cárcere, podemos perceber como Gramsci dá ao conceito um sentido amplo, definido como a elaboração de uma visão de mundo do ponto de vista de uma classe, consubstanciada em um projeto para si e para toda a sociedade sob a forma de uma "nova forma civilizatória” (DIAS, 1996a, p. 9). Assim, a hegemonia seria mais do que um mero conceito relacionado às alianças de classes ou a um domínio ideológico momentâneo, mas sim uma categoria mais ampla, que busca analisar como uma classe se alça sobre o restante da sociedade em sua luta por tornar-se domi nante, buscando universalizar seus interesses e criar uma direção que organize os demais setores sociais. Assim, a hegemonia envolve "coordenação, regulação, liderança e direção das demais forças sociais”, em uma luta que se inicia antes da tomada do poder político, culminando em uma "prática particular de consolidação das forças sociais e de sua condensação em um poder político com base de massas” (THOMAS, 2009, p. 194).

Com isso, essa categoria se mostra uma importante ferramenta para questionar a leitura tradicional feita sobre a metáfora da base/superestrutura de Marx. A hegemonia é exercida a partir de uma posição de classe, definida primordialmente pelas relaçóes sociais criadas historicamente pelo desenvolvimento do capitalismo e de sua estrutura produtiva. Isso mostra a ligação umbilical do conceito com as relações de produção, mas se manifesta de diferentes formas no tecido social, como, por exemplo, na cultura, com a "necessidade de estabelecer relações mais íntimas e seguras entre os grupos dirigentes e a massa popular-nacional, isto é, de reorganizar a hegemonia cultural” (GRAMSCI, 2000, t. 6, p. 231).

Embora sempre ligada às relações de produção e ao domínio de classe, a hegemonia é também um conceito dotado de historicidade. Em seu exercício, ela pode combinar dis- 
tintos elementos, assentando-se na "dialética entre direção/consenso e domínio/força, não conferindo uma separação ontológica entre ambas as categorias” (SOARES, 2017, p. 80). Essa combinação de elementos presentes no exercício da hegemonia faz dela um conceito que transita tanto no nível "estrutural” (pensando, aqui, nas relações de produção) como no nível "conjuntural”. A seguinte síntese aborda essa questão com maestria:

O processo de hegemonia se realiza tanto no plano do movimento quanto no plano das instituiçôes. Não faz, assim, o menor sentido reduzir Gramsci a um teórico da cultura ou das 'superestruturas'. Estamos falando da construção de uma racionalidade nova, distinta da anterior (...). Essa forma intelectual e moral deve, necessariamente, estar ligada a um programa de reforma econômica que é, exatamente, o seu modo concreto de apresentar-se. Pensar-se a construção de uma nova forma social, uma nova sociabilidade, só é possível se se pensam conjuntamente as formas específicas de sua realização - a um tempo material e simbólica. (DIAS, 1996a, p. 10)

Tendo exposto brevemente a amplitude do conceito de hegemonia, cabe, por fim, ressaltar a motivação de Gramsci para precisar tal arsenal teórico. O principal traço definidor da atividade de Gramsci era sua militância comunista no Partido Comunista Italiano, motivo pelo qual, inclusive, foi mantido encarcerado nos últimos anos de sua vida. Sendo assim, seus escritos estão ligados umbilicalmente com essa atividade política, e é a serviço dela que o marxista sardo criou suas elaborações sobre o conceito de hegemonia.

Esse alerta não é uma mera curiosidade biográfica, mas ajuda a elucidar o que motivava as reflexóes do autor sobre o tema. Ao discorrer sobre os diferentes aspectos da hegemonia, Gramsci buscava uma teoria que orientasse a luta dos comunistas naquele período de derrotas, materializadas na ascensão do fascismo na Europa. Assim, as elaborações teóricas de Gramsci sobre a hegemonia estão sempre relacionadas à luta pela construção da hegemonia do proletariado sobre as demais classes sociais que norteava o movimento comunista. Não resta dúvidas a respeito quando vemos sua referência à forma como o conceito foi cunhado por Lenin. Em seus escritos, à hegemonia burguesa sempre está contraposta uma hegemonia proletária, ainda a ser construída em uma luta na qual Gramsci se inscrevia completamente.

Ter isso em mente é importante, uma vez que os autores que analisaremos a seguir elaboram suas reflexões em um momento político distinto e de um lugar distinto aos de Gramsci. Não na militância dentro da Internacional Comunista ou nos cárceres fascistas, mas sim dentro de instituições acadêmicas europeias. Isso facilita a apropriação da obra gramsciana e do conceito de hegemonia em uma chave particular, transformando-as em categorias de 
análise para a construção de uma crítica negativa da sociabilidade capitalista, mas sublimando seu conteúdo político estratégico original.

O alemão Joachim Hirsch é um dos principais nomes do debate da derivação do Estado. Sendo movido desde o início de sua produção intelectual pela "tentativa de derivação da forma Estado a partir das categorias econômicas marxianas” (CALDAS, 2015, p. 134), Hirsch por vezes foi identificado como membro da Escola Lógica do Capital, vertente que te ria como foco justamente a derivação lógica tanto da forma estatal como de suas funções das categorias básicas da economia capitalista. Tal identificação é, no entanto, imprecisa.

Uma das principais críticas feitas aos pensadores de tal vertente é a desconsideração do desenvolvimento histórico concreto do Estado, elemento que tem um espaço crescente nas reflexóes de Hirsch com o passar dos anos. Como afirma o próprio autor em sua obra mais contemporânea, é importante analisar o surgimento histórico do Estado, uma vez que “as estruturas sociais são criadas através da ação humana, que está incrustada em condições históricas determinadas” (HIRSCH, 2010. p. 60).

O espaço que o desenvolvimento histórico do Estado toma no pensamento de Hirsch na porção mais recente de sua obra é ilustrado por sua interlocução com a teoria de regulação, formada principalmente por pensadores franceses que, a partir da década de 1980, se dedicaram a pensar "o significado das diferentes fases do desenvolvimento capitalista com suas estratégias de valorização características, suas formas político-institucional e suas relações sociais de força” (HIRSCH, 2010, p. 101). Com essa interlocução, o filósofo alemão busca um instrumental teórico que dê conta de um nível de abstração intermediário, mais concreto que o da forma política, para que seja possível compreender as mudanças internas do capitalismo e suas reverberações em suas formas político-institucionais.

Dessa interlocução, o autor alemão toma, principalmente, dois conceitos. O primeiro é o de processo de acumulação do capital, que caracteriza a forma determinada de produção em um determinado momento do capitalismo, composto por elementos que vão das técnicas de produção empregadas ao papel que as classes e grupos sociais cumprem no processo. Para que o processo de acumulação seja dotado de alguma estabilidade, é necessário que haja um sistema de regulação social, o outro conceito mobilizado por Hirsch, que seria 
uma rede de instituições e normas sociais que se encarregam de fazer com que as pessoas se comportem em concordância com as respectivas condições de acumulação, ou seja, que pratiquem os correspondentes modos de trabalho, de vida e de consumo, bem como as formas determinadas de asseguramento de seus interesses. (HIRSCH, 2010, p. 105)

É em conjunto com a categoria de regulação social que Hirsch mobiliza o conceito de hegemonia. Para que a regulação seja duradoura, diz o autor, é importante que ela tenha certo consenso social e uma disposição aquiescente voluntária, lembrando aqui os escritos de Gramsci a respeito da estreita relação entre coerção e consenso em toda relação de dominação. Sendo assim, “a implantação dos contextos de acumulação e de regulação relativamente estáveis está ligada com a hegemonia política e ideológica” (HIRSCH, 2010, p. 111). O autor assim define hegemonia, em uma longa passagem que convém ser reproduzida:

\begin{abstract}
Hegemonia, em sentido bastante geral, significa a capacidade de implantar representaçôes generalizadas, abarcando classes e grupos sociais, sobre o ordenamento correto e o desenvolvimento da sociedade; ou seja, a capacidade de conferir uma base para a ideia de que a ordem existente e suas perspectivas de desenvolvimento seriam, em geral, também capazes de incluir os interesses de setores subordinados da sociedade. Nesse sentido, uma relação hegemônica apresenta diversas dimensões: uma ideológica, relativa às representaçóes dominantes sobre valores e ordem; uma política, ou seja, a capacidade de fazer com que essas representações transformem-se em práxis de maneira convincente, incluindo, inclusive materialmente, amplas camadas populares; uma institucional, que se refere à definição do terreno institucional e das regras de acesso para os processos políticos de negociação e de decisão. (HIRSCH, 2010, p. 117)
\end{abstract}

Como se vê, o sentido de hegemonia tomado por Hirsch é próximo à concepção ampla de hegemonia advinda de uma leitura estrutural dos textos gramscianos. O sistema de regulação social vigente tem caráter conjuntural, relacionado às necessidades de coesão do processo de acumulação de capital, ligando-se ao aspecto mais amplo da hegemonia. Mais que apenas domínio ideológico, que inegavelmente existe, como Gramsci deixa claro ao afirmar que "toda relação de hegemonia é necessariamente pedagógica” (GRAMSCI, 1999, t. 4, p. 139), a hegemonia apresenta também dimensões políticas e institucionais, abarcando a forma material com a qual as classes subalternas são incluídas nesses âmbitos.

Se a hegemonia abarca instâncias ideológicas, políticas e institucionais, também mantém ligação estreita com o âmbito das relações de produção da sociedade. Para Gramsci, essa ligação se dá pelo foco na categoria de classe social, gerada materialmente pelas relaçóes de produção, como construtora da hegemonia em sua luta para tornar-se dominante. Para Hirs- 
ch, "tanto a estrutura geral da sociedade capitalista, como também os correspondentes modos de acumulação e regulação dominantes formam a base da hegemonia” (HIRSCH, 2010, p. 119), e essa ligação se dá mediada pelas formas sociais, entendendo-as, como exposto anterior mente, como as formas derivadas da própria reprodução da sociedade capitalista. Sendo assim, o próprio Estado, enquanto forma política do capitalismo, torna-se um dado fundamental para o estabelecimento da hegemonia. Assim sintetiza o autor:

\footnotetext{
Basicamente, são as formas sociais da própria sociedade capitalista que dão base para a hegemonia das classes dominantes, tornando-a possível. A "singularização" do Estado como corporificação da comunidade frente a todas as classes e frente aos cidadãos isolados é um requisito decisivo para que se formule e se imponha na realidade uma "política do capital" abrangente, para além da concorrência e dos antagonismos. (HIRSCH, 2010, p. 118)
}

Uma leitura muito difundida, presente em autores como Anderson (1986) e Eagleton (1997), vê em um primeiro momento da obra do marxista italiano a identificação da hegemonia com a sociedade civil, sendo ela o terreno no qual se desenvolve "a luta pela hegemonia” (GRAMSCI, 1999, t. 2, p. 168), visão essa que seria criticável por não ver o próprio papel do Estado em sua conformação. Posteriormente, o próprio autor teria desenvolvido o conceito, utilizando a hegemonia para criticar a dicotomia estanque entre Estado e sociedade civil presente na obra de Benedetto Croce, como sugere a célebre formulação "Estado = sociedade política + sociedade civil, isto é, hegemonia encouraçada de coerção” (GRAMSCI, 1999 , t. 3, p. 76).

Tal leitura, no entanto, carece de uma metodologia mais acurada para lidar com os Cadernos do Cárcere. Como demonstraram estudos filológicos realizados nas últimas décadas, aquela que seria a última formulação do conceito de hegemonia de acordo com Anderson na verdade data de um período anterior à sua suposta primeira aparição (FRANCIONI, 1984, p. 160). Esse erro contribui para uma má compreensão do substrato que há por trás da construção do conceito de hegemonia pelo autor e da maneira como ele mobiliza suas referências.

Em toda a elaboração dos Cadernos, não existe uma distinção orgânica entre sociedade civil e sociedade política, sendo a mesma usada apenas de maneira analítica. Gramsci, partindo de sua apropriação marxista dos escritos de Hegel, enfatiza a totalidade da articulação social, vendo a sociedade civil como "um conjunto de práticas e relações dialeticamente interpeladas pelo e integradas ao Estado" (THOMAS, 2009, p. 180). Assim, ocorre uma rela- 
ção dialética, não excludente e funcional entre sociedade civil e Estado, sendo ambas vistas como níveis “superestruturais” mutuamente dependentes.

Quando analisamos essa questão partindo da leitura feita por Gramsci da metáfora da base/superestrutura, que afasta qualquer reducionismo que se aponte à sua aparição no prefácio de 1859 de Contribuição para a crítica da economia politica (2003, p. 5) de Marx, vemos a riqueza com que o autor integra sociedade civil, Estado e relações de produção em sua teoria. Gramsci vê as superestruturas como formas ideológicas que prosperam de e se relacionam com uma estrutura econômica dada historicamente e entendida como o conjunto de relações sociais nas quais os seres humanos se movem e existem (THOMAS, 2009, p. 101).

Assim, para Gramsci, a hegemonia é um elemento de coesão do próprio Estado, servindo como elemento de conexão entre a sociedade civil e política e as relações de produção. Já Hirsch demonstra como o exercício da hegemonia depende do funcionamento das formas sociais, com destaque para a forma política, dado essencial para a criação de uma "política do capital” que se alce sobre os antagonismos presentes no tecido social. Assim, Hirsch, com sua análise da forma política e dos seus efeitos na sociedade, propóe uma leitura complementar à exposta por Gramsci, demonstrando a determinação recíproca existente entre o exercício da hegemonia e o funcionamento da forma política.

\section{BOB JESSOP: ESTRATÉGIAS DE ACUMULAÇÃO E PROJETOS HEGE- MÔNICOS}

O britânico Bob Jessop foi um dos pensadores de fora da Alemanha que participaram do debate. Em sua obra Capitalist State, o autor destaca os avanços coletivos que os teóricos da derivação lograram para a compreensão do Estado capitalista. No entanto, aponta a insuficiência dessa perspectiva em trabalhar com a análise histórica concreta, além da visão restrita a respeito da luta de classes que possui. Para superar tais limites, seriam necessários conceitos que dessem conta de um grau de abstração mais concreto, ferramental teórico este que os derivacionistas não teriam desenvolvido (JESSOP, 1982, p. 141).

Com essa preocupação em mente, Jessop busca em Gramsci as categorias necessárias para analisar as bases sociais do poder estatal. O britânico reputa ao sardo a ruptura teórica no marxismo responsável por deixar de se compreender o Estado apenas como um aparato de coerção de uma classe sobre as demais, focando no relativo balanço existente entre "coer ção, fraude e consenso ativo" (JESSOP, 1982, p. 141). 
$\mathrm{Na}$ apropriação feita por Jessop das categorias de Gramsci, o conceito de hegemonia é, sem dúvidas, o principal. No entanto, essa apropriação se dá pela mediação de Nicos Poulantzas, teórico que, segundo Jessop (1982, p. 153), não se limitou a interpretar e tentar dar coesão à obra de Gramsci, fazendo uma leitura original da mesma para formular uma abrangente teoria política. Bob Jessop assim sintetiza a questão:

\begin{abstract}
Poulantzas considera que a hegemonia opera não apenas para assegurar o consentimento ativo das classes dominadas, mas também para unificar as classes ou fraçôes da classe dominante em um bloco de poder coerente. Ele segue Gramsci na argumentação de que a dominação política de classe no capitalismo repousa sobre uma distinta combinação de consentimento ativo articulada com formas institucionalizadas de coerção. Mas ele também amplia o trabalho de Gramsci ao argumentar que a fragmentação econômica da burguesia só pode ser superada através de um Estado que apresente sua própria unidade interna (de classe) e autonomia institucional frente às fraçốes da classe dominante. (JESSOP, 1982, p. 155)
\end{abstract}

Assim, o conceito de hegemonia em Poulantzas torna-se uma ferramenta para avaliar não apenas os aspectos da dominação de classe que não são relacionados diretamente à coerção, mas também as próprias relaçôes internas à classe dominante. A partir dessa ideia, Poulantzas desdobra seu aparato conceitual voltado à compreensão do Estado no nível das formaçôes sociais, isto é, em um grau mais concreto do que a análise da forma estatal a partir das determinações do modo de produção capitalista.

Não é o objetivo do presente trabalho analisar a obra de Poulantzas, mas cabe apontar que tal utilização instrumental da categoria de hegemonia voltada a analisar equilíbrios de poder internos ao bloco dominante corre o risco de transformá-la em uma categoria sociológica descolada das determinações mais profundas do modo de produção capitalista. Não à toa, Poulantzas $(1985$, p. 32) demarca no início de sua última obra a importância do conceito de classe enquanto derivada das relações de produção, afirmando que os lugares de classe se traduzem em poderes que se manifestam na luta de classes e no próprio Estado.

Como aponta Caldas (2015, p. 208), Jessop, então, se apropria do aparato conceitual gramsciano, mediado pela leitura proposta por Poulantzas, para levar a frente seu objetivo: desnudar a dialética existente no Estado entre as determinações estruturais do modo de produção e os aspectos conjunturais relacionados às posições de classe. Ao realizar sua análise, no entanto, ele se depara com um problema metodológico ao afirmar que, sendo o aparato e o poder estatais frutos de múltiplas determinações, é necessário enxergá-los como resultantes de múltiplas correntes causais. Assim, os grandes conceitos como poder, interesses e estrutura só 
poderiam ter significado quando analisados a partir das relaçôes concretas existentes naquela formação social específica. A essa visão o autor dá o nome de abordagem "estratégico-relacional", fundada no "reconhecimento de que a estrutura precisa ser definida relacionalmente" (JESSOP, 1982, p. 253), ou seja, o "momento estrutural” e o "momento conjuntural” variam de acordo com a situação concreta.

Com isso, Jessop acaba por utilizar o conceito de hegemonia de maneira reducionista. A luta por hegemonia, em sua obra, se dilui em projetos hegemônicos, que, quando bem-sucedidos, conformam consensos temporários em uma determinada conjuntura. Seu objetivo com essa operação é superar a leitura estática feita por muitos autores a respeito da hegemonia, enfatizando, em seu lugar, "o movimento dinâmico de liderança visando determinados objetivos em conjunturas específicas” (JESSOP, 1983, p. 89).

No entanto, o autor britânico acaba secundarizando as determinações das formas sociais sobre a ação dos indivíduos, destacando desproporcionalmente na análise a dimensão estratégica existente em tais ações. Como o mesmo aponta, sua abordagem rejeita "as tentativas de capturar a 'essência' do Estado", visando "elaborar ferramentas teórico-metodológicas úteis para estudar as mudanças em suas formas, funçôes e efeitos” (JESSOP, 2016, p. 54). Assim, as determinaçóes advindas da forma valor e do modo de produção capitalista sobre o Estado e suas funções não ficam claras, fazendo com que as menções a esse grau de abstração apareçam descoladas do real foco dos escritos, que é a dimensão da política e das relaçóes sociais nas quais o Estado atua concretamente.

Conforme aponta Hirsch (2006, p. 50-51), essa leitura, ao ignorar a coerção da forma à qual estão sujeitos os indivíduos, leva à cisão entre ação e estrutura, o que torna das determinações advindas do modo de produção por demais abstratas e desconexas com a realidade concreta, dificultando a compreensão dos fenômenos que envolvem a reprodução capitalista. Para tanto, Bob Jessop faz uma apropriação do conceito de hegemonia próxima à leitura reducionista que se tornou muito difundida especialmente a partir dos escritos de Norberto Bobbio (BIANCHI, 2008, p. 173), utilizada para fundamentar uma separação estanque entre estrutura e superestrutura. Ainda que se declare que se faz o contrário em nome do combate ao economicismo, o resultado real acaba sendo a supervalorização dos elementos conjunturais frente as determinações mais profundas do modo de produção capitalista. 
Por fim, cabe destacar como ambos partem de uma base comum ao se referirem à obra de Antonio Gramsci, vendo-o como uma ruptura no marxismo de sua época, em especial com relação aos escritos de Lenin. Joachim Hirsch (2010, p. 6) destaca Gramsci como inaugurador do "marxismo ocidental”, em contraposição a um "marxismo soviético" que vê o Estado apenas como aparato de repressão de classe, sem delimitar com precisão que autores comporiam tal generalização. Já Bob Jessop destaca como Gramsci avançou "para além da redução leninista do Estado um grande aparato repressivo” (JESSOP, 2016, p. 105).

Essa visão é tributária dos escritos de Luciano Gruppi, segundo o qual o sardo teria em um primeiro momento sido influenciado diretamente por Lenin em sua concepção de hegemonia ligada à luta pela ditadura do proletariado, para, posteriormente, operar "um enriquecimento da concepção leniniana do Estado, no momento em que o Estado não é mais unicamente concebido como máquina opressora e que, portanto, deve ser destruída” (GRUPPI, 1978, p. 88). Essa leitura de Gramsci estava na base da formulação do eurocomunismo, vendo nele a fundamentação teórica para o abandono da estratégia revolucionária, em prol de uma política voltada à disputa por espaços institucionais na luta pela hegemonia.

Tal perspectiva é fruto de uma distorção dos escritos de Gramsci. É verdade que, em relação à construção do conceito de hegemonia, a posição de Gramsci diante de Lenin é marcada por aproximaçóes e distanciamentos, ligados mais especificamente às divergências táticas com relação ao papel do Estado na transição pós-Revolução Russa de 1917 (BIAGIO, 2010, p. 111-114). No entanto, em momento algum o marxista italiano declarou ter abandonado os fundamentos leninistas de seu pensamento, estando já presentes em Lenin apontamentos importantes sobre o papel não coercivo do Estado (CUEVA, 2004, p. 170). Gramsci, tendo diante de si uma Itália dominada pelo fascismo, abria uma divergência com as táticas adotadas pela Internacional Comunista, que ignorava as especificidades de sociedades como os países da Europa Ocidental, mas se mantinha alinhado aos objetivos estratégicos do movimento comunista internacional, a serviço disso estavam suas elaboraçôes teóricas.

\section{CONCLUSÃO}

Em síntese, Joachim Hirsch utiliza o conceito de hegemonia sem diluir suas determinações advindas do modo de produção capitalista, utilizando-o em conjunto com o ferramental da teoria da regulação para abordar níveis mais concretos que os das formas sociais. Bob Jessop, por sua vez, evidencia de maneira desproporcional o aspecto político em sua 
análise, fazendo do conceito de hegemonia algo determinado quase que exclusivamente por elementos conjunturais, ignorando as determinações mais gerais. No entanto, ambos partem de uma leitura de Gramsci que equivocadamente o afasta dos debates orgânicos da Internacional Comunista em sua época, empobrecendo suas construçôes conceituais por afastá-lo das influências que recebeu, em especial da obra de Lenin. 
Gramsci e o debate da derivação do Estado: o conceito de hegemonia em Joachim Hirsch e Bob Jessop

REFERÊNCIAS BIBLIOGRÁFICAS

ANDERSON, P. Antinomias de Gramsci. Crítica Marxista. São Paulo, n. 1, p. 7-74, 1986.

BIAGIO, A. Di. Hegemonia leninista, hegemonia gramsciana. Brasília: Astrojildo Pereira/ Rio de Janeiro: Contraponto, 2010, p. 87-114.

BIANCHI, A. O laboratório de Gramsci. São Paulo: Alameda, 2008.

CALDAS, C. O. A teoria da derivação do Estado e do direito. São Paulo: Outras Expressões, 2015.

CUEVA, A. La teoria marxista: categorías de base y problemas actuales. Quito: PCMLE, 2004 .

DIAS, E. F. Hegemonia: racionalidade que se faz história. In: DIAS, E. F. et al. O Outro Gramsci. São Paulo: Xamã, 1996, p. 9-80.

DIAS, E. F.. Sobre a leitura dos textos gramscianos. In: DIAS, E. F. et al. O Outro Gramsci. São Paulo: Xamã, 1996, p. 105-122.

EAGLETON, T. Ideologia. São Paulo: UNESP, Boitempo, 1997.

FRANCIONI, G. L'officina gramsciana: Ipotesi sulla strutttura dei 'Quaderni del carcere'. Nápoles: Bibliopolis, 1984.

GRAMSCI, A. Cuadernos de la cárcel. Cidade do México: Era/Benemérita Universidade Autônoma de Puebla, 6 t., 1999/2000.

GRUPPI, L. O conceito de hegemonia em Gramsci. Rio de Janeiro: Graal, 1978.

HIRSCH, J. Forma política, instituições políticas e Estado - II. Crítica Marxista. São Paulo, n. 25 , p. 47-71, 2006. 
HIRSCH, J. Teoria materialista do Estado. Rio de Janeiro: Revan, 2010.

HIRSCH, J; KANNANKULAM, J.; WISSEL, J. A teoria do Estado do "marxismo ocidental”: Gramsci, Althusser, Poulantzas e a chamada derivação do Estado. Direito e Práxis. Rio de Janeiro, v. 08, n. 1, p. 722-759, 2017.

HOLLOWAY, J.; PICCIOTTO, S. Introduction: towards a materialist theory of the state. In: HOLLOWAY, J.; PICCIOTTO, S. State and Capital: A marxist debate. Londres: Edward Arnold, 1978, p. 1-31.

JESSOP, B. Capitalist State: Marxist Theories and Methods. Oxford: Martin Robertson, 1982.

JESSOP, B. Accumulation, State and Hegemonic Projects. Kapitalistate. Berkeley, n. 10/11, p. 89-111, 1983.

JESSOP, B. The State: Past, Present, Future. Cambridge: Polity Press, 2016.

LIGUORI, G.; VOZA, P. (Orgs.). Dicionário gramsciano. São Paulo: Boitempo, 2017.

MARX, K. Contribuição à crítica da economia politica. São Paulo: Martins Fontes, 2003.

MARX, K. O capital. São Paulo: Boitempo, v. 1, 2011.

MÍGUEZ, P. El debate conteporáneo sobre el Estado en la teoría marxista: su relación con el desarollo y la crisis del capitalismo. Estudios Sociológicos. Cidade do México, v. 28, n. 84, set./ dec. 2010.

OSÓRIO, L. F. B. A teoria da derivação do estado e o debate (alemão) do mercado mundial. Revista Debates. Porto Alegre, v. 13, n. 1, p. 17-39, 2019.

POULANTZAS, N. O Estado, o poder, o socialismo. Rio de Janeiro: Graal, 1985. 
Gramsci e o debate da derivação do Estado: o conceito de hegemonia em Joachim Hirsch e Bob Jessop

SOARES, M. A. O direito em contraponto a partir do itinerário da teoria geral da hegemonia de Antonio Gramsci. Tese (Doutorado em Direito), UFPR,Coritiba, 2017.

THOMAS, P. D. The Gramscian Moment: Philosophy, Hegemony and Marxism. Leiden: Koninklijke Brill, 2009. 